\title{
Serum CEA Level Low
}

National Cancer Institute

\section{Source}

National Cancer Institute. Serum CEA Level Low. NCI Thesaurus. Code C162046.

The amount of carcinoembryonic antigen present in a serum sample is low. 